\title{
AMBIENTE DE TREINAMENTO DE ACOMPANHANTES DE PORTADORES DE TRANSTORNO ESPECTRO AUTISTA EM REALIDADE VIRTUAL
}

\author{
Thiago Pina Soares \\ Instituto de Tecnologia - ITEC \\ Belem, Brasil \\ thiagopina.soares@gmail.com
}

\author{
Marco Antonio P. de Souza \\ Inst. de Computação - UFAL \\ Maceió, Brasil \\ maps@ic.ufal.br
}

\author{
Leonardo B. Marques \\ Centro de Educação - UFAL \\ Maceió, Brasil \\ leonardo.marques@cedu.ufal.br
}

\author{
Dionne C. Monteiro \\ Inst. de Ciências Exatas e \\ Naturais - UFPA Belém, Brasil \\ dionne@ufpa.br
}

\begin{abstract}
RESUMO
Com o avanço tecnológico da ultima década, e notável o uso da tecnologia para ajudar e dar assistência em diferentes áreas de estudo, como a medicina, fisioterapia, psicologia, etc, já que possibilita informações mais específicas e detalhadas para seu estudo, o que facilita a analise de resultados. A Realidade Virtual (RV) e um exemplo de tecnologia que continua crescendo nas ultimas décadas e vem se tornando popular dentre essas áreas de estudo devido ao seu grande potencial de possibilitar uma ambiente virtual de imersão que pode simular qualquer situação e também tem a possibilidade de gerar resultados que podem ser comparados aos resultados reais.
\end{abstract}

\section{Palavras-Chave}

Realidade Virtual; Tecnologia Assistiva;

\section{INTRODUÇÃO}

Com o avanço da tecnologia nos últimos anos, é notório cada vez mais o uso da mesma para a ajuda e acompanhamento dos mais diversos assuntos e temas, como na medicina, fisioterapia, psicologia, pois ela proporciona um maior acesso às informações, assim como facilita a análise de resultados específicos destas áreas citadas. A Realidade Virtual (RV) é um exemplo de tecnologia que vem crescendo e se tornando cada vez mais popular neste meio, visto que esta tem o potencial de disponibilizar a imersão em um ambiente simulado em qualquer área que possa ser aplicada, além de gerar resultados que podem ser comparados a resultados reais.

\footnotetext{
Permission to make digital or hard copies of all or part of this work for personal or classroom use is granted without fee provided that copies are not made or distributed for profit or commercial advantage and that copies bear this notice and the full citation on the first page. Copyrights for components of this work owned by others than the author(s) must be honored. Abstracting with credit is permitted. To copy otherwise, or republish, to post on servers or to redistribute to lists, requires prior specific permission and/or a fee. Copyright 2018 SBC.

IHC 2018, Anais Estendidos do XVII Simpósio Brasileiro sobre Fatores Humanos em Sistemas Computacionais

Outubro 2226, 2018, Belém, Brasil

PÔSTERES VIRTUAIS E DEMOS
}

Diante deste crescimento, pessoas das demais áreas procuram cada vez mais o uso da tecnologia de RV para simular ambientes virtuais em busca de uma análise mais profunda e de resultados que possam ser aplicados em situações reais. Recentemente, as tecnologias baseadas em $\mathrm{RV}$ têm proposto inovações e se tornado cada vez mais utilizadas e acessíveis, possibilitando a visualização de estímulos de uma forma mais próxima ao que já existe no dia-a-dia[1].

$\mathrm{O}$ caso deste projeto leva em conta crianças que sofrem com o Transtorno Espectro Autista (TEA). O autismo refere-se a certas condições que se caracterizam por dificuldades e desafios com habilidades sociais, tais como falta de comunicação e repetição de comportamentos. Segundo o Jornal de Pediatria do Rio de Janeiro [2], houve nas últimas décadas um aumento drástico em relação às crianças diagnosticada com algum tipo de Transtorno Espectro Autista, chegando a atingir 1\% das crianças.

\section{METODOLOGIA}

Para a coleta de ideias que poderiam ajudar na criação do ambiente virtual interativo, foi realizada uma pesquisa sobre a influência da Realidade Virtual e seu verdadeiro impacto perante as demais áreas que foram em busca da tecnologia como método alternativo de tratamento para seus pacientes, visto que a mesma já é utilizada em diversas áreas de estudo como treinamento, aviação e até mesmo na área da saúde [3] Foi concluído que o uso da RV realizados nesses estudos mostrou sua eficácia de forma a confirmar que o projeto poderia ser realizado com êxito.

O sistema consiste de sessões onde o pai/especialista escolhe determinados estímulos para utilizar durante a sessão. Estes estímulos são escolhidos por pares e apresentados para o paciente, onde o mesmo deve escolher o de sua preferência. Após análise desses estímulos durante a sessão, o pai deve fazer o registro de escolhas assim como a futura análise dos resultados obtidos. 
Estas interações têm como objetivo não somente verificar o comportamento da criança em resposta às interações do usuário, mas também verificar seus interesses por cada estímulo que lhe foi apresentado. Como a criança terá preferência por certos estímulos, haverá a troca destes durante a sessão de modo a se verificar o de maior interesse da criança e assim gerar os resultados que serão extraídos da sessão para uma melhor análise por parte dos especialistas.

Estes dados têm como objetivo uma melhor análise por parte dos especialistas que pretendem ajudar os pais durante este tratamento. Dependendo da ação do usuário ou se o mesmo demorar demais ou, ainda, agir muito rápido, o modelo da criança poderá agir de formas diferentes, como formas de resposta ao comportamento do próprio pai. Dessa forma, estas informações vêm com propósito de auxiliar estes usuários a saberem lidar da melhor forma com suas crianças, tendo em vista uma melhoria de suas ações em cada sessão que segue.

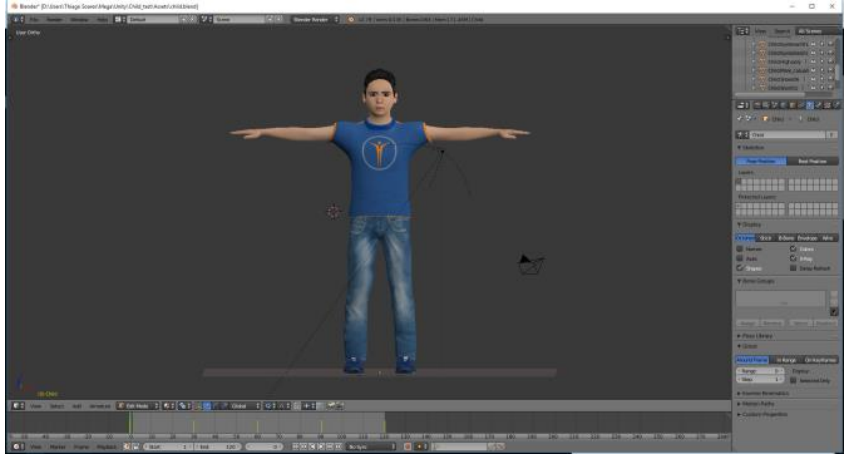

Figura 1. Modelo da criança utilizado no simulador interativo

Após terminar o desenvolvimento do projeto, é necessário a compila-lo e realizar a sua build, isto é,criar o projeto executável para cada versão desejada para que assim seja possível sua utilização fora do motor gráfico. Esta build também conta com certas configurações para cada versão, tais como alocação máxima de memória para a versão web e ajustes de tamanho de tela, para que haja o redimensionamento desta dependendo de onde o sistema está sendo executado.

O projeto é composto por duas versões, sendo uma para Desktop, com a utilização do Oculus Rift e outra utilizando a API WebGL. A primeira tem como objetivo uma maior sensação de imersão no ambiente virtual, objetivando uma experiência mais próxima à que ocorre em sessões reais. Já a segunda conta como uma alternativa online para o projeto, visto que nem sempre o Oculus Rift estará disponível para a realização da sessão.

Além do simulador em sim como resultado, um teste de usabilidade foi realizado com 8 pessoas, sendo coletados dados dos participantes como gênero, formação acadêmica, tempo de experiência com a população no TEA, além de um questionário referente às suas respectivas experiências quanto ao uso do simulador, objetivando uma coleta de dados que poderá servir para a realização de futuros trabalhos além de verificar o que se poder melhorar dentro do sistema para uma melhor experiência da parte do usuário.

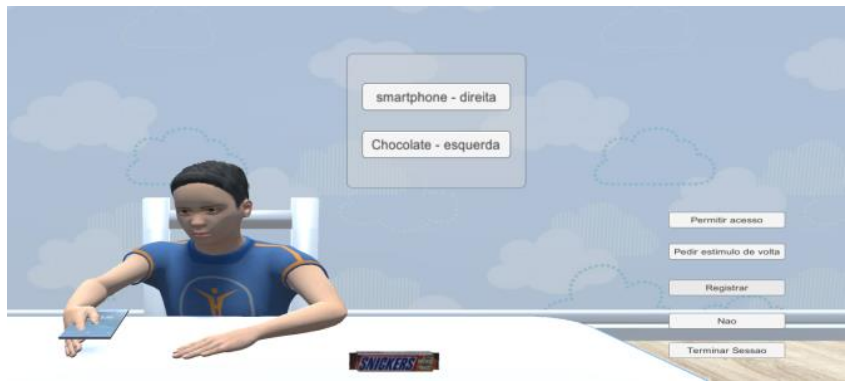

Figura 2. Exemplo de sessão dentro do ambiente virtual

\section{CONCLUSÃO}

O presente trabalho mostra uma nova alternativa de treinamento para pessoas que necessitam interagir com pessoas com TEA para que estejam prontas para comportamentos mais comuns nestes indivíduos. Já para profissionais da área, esta proposta tem como objetivo fornecer dados necessários para uma melhor análise comportamental não só da criança, mas também dos pais, tornando possível não só um melhor acompanhamento como também decidir um melhor caminho e etapas a serem seguidas para o tratamento da criança.

Verificou-se, a partir do questionário, que algumas mudanças podem ser realizadas para a melhoria na interação entre o usuário e o ambiente virtual. Outro ponto a ser analisado é a parte de consequências adequadas para a continuação da sessão, assim como a etapa de feeback para uma melhor experiência e interação para os jogadores.

De acordo com o feedback dos usuários que fizeram testes na ferramenta, este projeto possui potencial para inovação, além de trabalhos futuros que podem surgir a partir deste. Além disso, o projeto pode contribuir significativamente com um melhor acesso às informações sobre 0 comportamento destas crianças, facilitando o acesso às pessoas que tem interesse em saber mais ou que precisam se informar mais sobre o problema em questão.

\section{REFERÊNCIAS}

1. L. M. Ana Ribeiro, “A indução afetiva em cenários de realidade virtual: avaliação da sensação de presença," Psicol. clin. vol.27 no. 1 Rio de Janeiro, pp. 139-160, 2015.

2. P. V. Annio Posar, "Autismo em 2016: necessidade de respostas," J. Pediatr. (Rio J.), vol. 93, pp. 111-119, Abril 2017.

3. C. R. França e T. d. Silva, "A utilização da Realidade Virtual e Aumentada no Ensino de Ciências no Brasil," Revista Brasileira de Pesquisa em Educação e Ciências - RBPEC, Julho 2017. 